\title{
Empirical results of the awareness of social media and its application by academics in teaching in New Zealand
}

\author{
Michael C. Cant \\ Department of Marketing and Retail Management \\ University of South Africa, South Africa \\ Pieter Nel \\ Business and Enterprise Network \\ Unitec Institute of Technology, New Zealand \\ Johannes A. Wiid \\ Department of Marketing and Retail Management \\ University of South Africa, South Africa \\ Denisa Hebblethwaite \\ Business and Enterprise Network \\ Unitec Institute of Technology, New Zealand
}

\section{Keywords}

Social media, academics, education, Facebook, Twitter, students, social networks

\begin{abstract}
Academics and students across the globe are increasingly using social media (SM) for personal interactions, social connections and educational purposes. The article reviews the awareness and use of SM in teaching by academics and whether they can utilize this platform for effective communication to engage students in learning activities. The overall objective of this research study is to identify how academics can best integrate SM into traditional teaching methods by examining both the advantages and disadvantages of this innovative medium.

The research study was conducted during 2015 at a New Zealand tertiary educational institution in a business school comprising various departments. A total of 58usable responses were obtained via an E-survey using survey monkey and then analysing the responses. Suggestions are made to educators regarding a viable social digital educational environment using SM. It is concluded that academics are communicating with students in a positive way via the use of SM for educational purposes and that much scope exists to improve the use of SM for educational purposes by academics.
\end{abstract}

Corresponding author: Michael C. Cant

Email address for corresponding author: cantmc@unisa.ac.za

First submission received: 13th April 2017

Revised submission received:19th June 2017

Accepted: 16th August 2017

Note

The terms "educator, academic and teacher" are used interchangeably in this article.

\section{Introduction}

The evolution of social media (SM) in the contemporary world has been meteorically increasing between 2000 and 2010. Today it permeates all spheres of life; no matter whether it is digital media being used for a business to speed up recruitment processes or for internal communication between staff (Rahman, Arora \& Kularatne 2014). Furthermore, the fast-moving world of today has placed new demands on communication systems and particularly the younger generation $\mathrm{Y}$ who are notoriously impatient, are demanding instant feedback on a variety of issues in the social environment. Dixon (2015:9) claims that worldwide there are over 2 billion users of SM and 
covers $40 \%$ of all people with an internet connection. Face book alone has the greatest use with more than 1.3 billion people globally. It is thus clear why academics have also embraced electronic media in their teaching to transfer knowledge and improve the learning experience of students. It is also generally believed that SM technology usage in teaching enhances student participation, engagement, and communication. It also strengthens relationships between academics, students and communities (Retta 2012).

In a broader context, note should be taken of the role of eLearning. It is pointed out by Young (2014) that eLearning is the delivery of content to individuals and groups via the Internet and is enabled by the support of Information Computer Technology (ICT). It is therefore unsurprising that eLearning and SM go hand in hand to enhance student learning as means used by academics to enrich students' learning experiences. Internet based SM technologies are designed and developed to improve social connections of a community. SM applications include Facebook, Google Plus, YouTube, Pinterest, Twitter, Whatsapp, Snapchat, Instagram and Web Blogs, all of which have become very popular among students and educators.

In view of the growing importance of SM, it is clear why the need for the use thereof has been accommodated in the educational environments in various countries (Wiid, Nell \& Cant2015; Lupton 2014). It is also the case in New Zealand where this article reports on the awareness and use of SM by academics at a tertiary institution.

The purpose of this research project is to determine academics' awareness of SM networking systems and their view on using it. The objective is to determine the following:

1. The awareness of academics regarding SM media as a lecturing tool.

2. The use of SM by academics to enhance student learning.

3. The relationship between SM as a lecturing tool and the personal use of SM by academics.

The next section provides an overview of SM networking systems as well as the awareness and uses of SM networking systems. The empirical findings and the discussion of the findings are presented after the literature review had been executed.

\section{Literature review}

\subsection{General theory}

Electronic communication has become a very popular and highly preferred means of communication in organisations for a variety of purposes (Research New Zealand,2015 White,Vanc \& Stafford 2010; Welch 2012). Even though email is currently the preferred method of internal communication (Welch 2012), the Society for Human Resource Management (SHRM2012) state that there is an increasing trend of using SM for communication purposes in the workplace. The use thereof in the education environment is therefore a logical progression in the educational process.

SM is defined by SHRM (2012 Par 1) as "web-based tools and technologies used to share information and turn communication into interactive dialogue with internal and external audiences through Facebook, LinkedIn and Twitter". Mangold \& Faulds (2009: 357) define SM somewhat differently as "... a variety of new sources of online information that are created, initiated, circulated and used by consumers intent on educating each other about products, brands, services, personalities and issues."The Education Council NZ, (2015a) outlines what social media entail as shown in Figure 1.As a further refinement to describe more fully what SM entail, the Education Council NZ,(2015a) outlines the characteristics of SM as follows:

1. Internet based platforms that enable all the users to: create, adapt, share and sustainably reuse the information and content. It enables the users to engage in digital collaboration and dialogue. It provides linkages to create groups, networks and communities.

2. Users are able to have, initiate and continue social interactions with peers and other users. Create and maintain their online profiles and IDs.

3. SM applications are largely public online platforms that are accessible $24 / 7$ through different locations and most computer \& mobile devices. 
4. Content and information on SM is largely created by the users, persistent and can be subject to conditions of use.

Figure 1. What is Social Media?

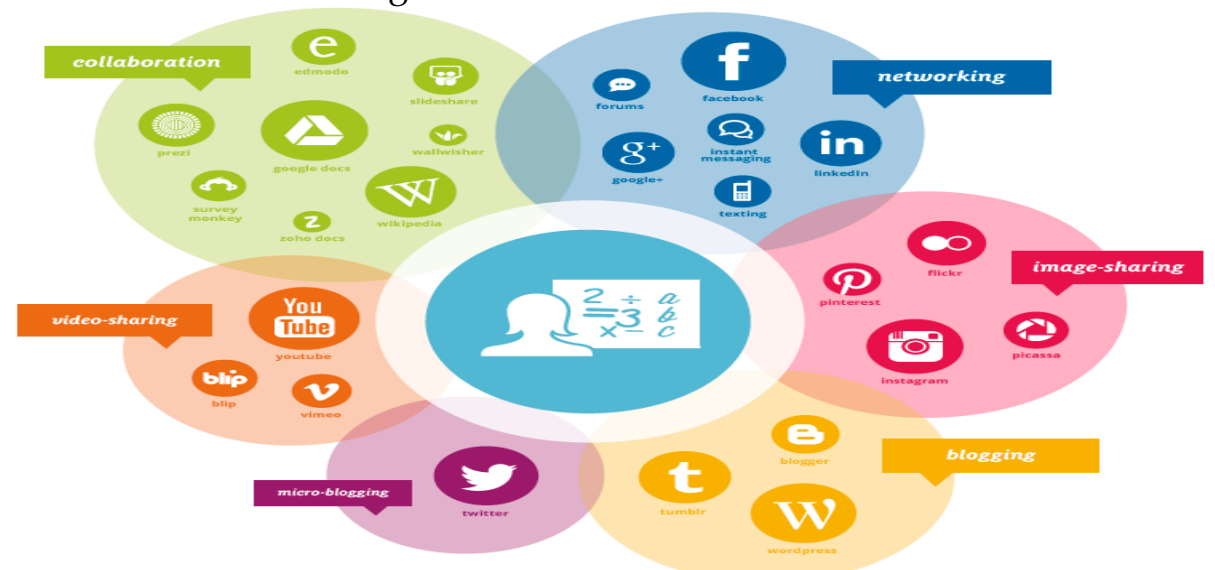

Source: Education Council NZ, (2015a)

Social networking creates a virtual culture based on diversified media systems that use computer/mobile mediated communication. The best part of a SM culture is that the content is created by the audiences and it is based on the principal of sharing and participation. When using SM people not only create content, but go on to make conversations and communities using openness and connectedness (Huang 2014).

The educational publishing company Pearson in the USA regularly executes surveys using representative samples of American faculty members. Results reported by Seaman and Tinti-Kane (2013: 7-14) indicate that more than half (55 per cent), use SM for professional purposes other than teaching, but only 41 per cent did so for teaching purposes. LinkedIn was the site most used for professional purposes other than teaching, followed by blogs and wikis, Facebook, podcasts and Twitter. For teaching purposes, blogs and wikis are most used, followed by podcasts, LinkedIn, Facebook and Twitter. Lupton(2014:13) on the other hand found that in response to the question in her survey, about which SM the respondents found most useful for their academic work, Twitter was very strong (83\%), followed by a much lower response re Academia.edu (23\%), a personal blog (16\%), Facebook (14\%), LinkedIn (14\%), online referencing tools $(11 \%)$,YouTube $(10 \%)$, a multi-authored blog $(7 \%)$, Google+ $(5 \%)$, Slide Share $(5 \%)$ and curation tools $(4 \%)$. Other tools listed (Wikipedia as an author/editor, Pinterest, Instagram, Tumblr, Flickr and Quora), attracted less than $2 \%$ of responses.

The research reported by various authors as outlined above, clearly shows varying results which could be refined by more reporting of research investigations such as this study's reporting in the current research.

\subsection{Benefits of the Social Media for Academics}

Lupton (2014) states that there are various published reports and surveys outlining the usefulness, benefits and drawbacks of SM usage by academics and students in the recent years. The results and recommendations of research reports offer insight into how academics strategically use SM in a sophisticated way to reap many benefits in their academic endeavours. The benefits of SM includes connecting and creating networks, not only with students and other lecturers, but also with people outside universities which promote openness, giving and receiving supports and social sharing. The reports and research on SM have largely been positive, however, certain people have also raised concerns in regards to issues related to privacy, professionalism, injudicious users, ethical usage, time pressures, and lack of credibility and problems of possible plagiarism.

Lupton (2014) further highlights that for teaching purposes, Wikipedia and blogs are useful along with YouTube, podcasts, LinkedIn, Facebook, and Twitter. By creating SM ecosystems, 
academics can use a variety of sophisticated tools and platforms to reap many benefits in academic practices. The following are listed as benefits of SM use in academic practices:

1. Creates a culture of sharing and building new connections.

2. Provides real time rapid access to vast professional networks.

3. Enable users to make more direct conversations and influences.

4. Help students to keep in contact with their teachers.

5. Provides the ability to chat and start conversations any point of time.

6. Easy to disseminate information to a large audience.

7. Strong networking is possible through SM which is otherwise a difficult task.

8. Provides access to unlimited up to date information and support that can be utilized for various purposes.

9. Interactions and connections between diversified people which is otherwise not possible.

10. The increased ability to access information with mobile units facilitates and simplifies the possibility of increased electronic communication.

11. Keep track of information/opportunities internationally by following key players, leaders and authors.

12. Fast and very effective way of communicating with students.

13. Great tool to increase student engagement and interaction both in class and at home.

SM thus has the potential of transforming the fundamental nature of education and academic writing as well. Scholarship and knowledge creation is enhanced by using SM due to the sharing and participation culture of SM platforms. Nel (2013) also points out that users of SM should encourage and promote two-way communication so that the transfer of information is fair and effective to all concerned. Users should also be in a position to utilise innovative ideas from all participants to gain excellence in desired educational outcomes.

\subsection{Social media in New Zealand}

The awareness and use of SM in New Zealand has, amongst others, been researched by Fuatai (2012) when the Kelly Global Workforce Research project was executed. The New Zealand results in 2012 indicated that 23\% of Generation Y (aged 19-30); 22\% of Generation X (aged 41-48) and $15 \%$ of baby boomers (49-66), found the use of SM in the workplace acceptable. These results clearly indicate that there is a greater awareness and use of SM amongst the younger generation, which would probably include the primary group participating in educational activities to prepare them for their careers. The follow on would be that the use of SM by academics to communicate and use it as part of their educational tool kit for student education is appropriate (Lupton 2014; Neal 2012).

Dixon (2015:9) outlined a number of important elements in terms of the awareness and use of $\mathrm{SM}$ in New Zealand. Four out of five New Zealanders with an internet connection have SM accounts with $87 \%$ of those using Facebook. It has also become the norm in New Zealand that businesses interact with their clients via SM when dealing with complaints or announcing offers or good deals. Dixon (2015:10) also points out that there is an awareness by the community at large that different SM options exist and that they should use a social platform that suits them personally. Apart from Facebook or Twitter, there are also other platforms such as the friendlier picture driven Instagram and on the other hand, the more touchy-feely approach of Vine which could also be used. Alternatively, users could also use Pinterest. Practically speaking professional users appear to make more use of LinkedIn.

The Education council NZ (2015b) also identified SM as an effective tool to engage students and for creating an effective communication channel with parents and communities. NZ academics are also encouraged to use SM to help students to grow positive behaviour and enable them to apply respectful values in all interactions on SM platforms. For educational institutions and academics the 
use of SM as a toolkit for educational purposes, has therefore become imperative to improve educational delivery and learning of students (Retta 2012).

\subsection{Downsides to the usage of social media}

Some critics argue that there are downsides regarding the usage of SM and it presents several legal and security related concerns for institutions. Since SM is a public platform, users, both sending and receiving, should be clear that it should not be taken seriously and personally, as it is merely a communication media. Various cases of bullying and even suicide cases have been recorded where the indulgence has become so severe that people have not been able to extract themselves from SM consequences on their personal lives (Taylor 2015).

Excessive use of SM usage is bad because students often show signs of addictions to SM. This compulsiveness and its symptoms have a significant negative impact on the academic performances of the students and consequently on the SM. Huang (2014) points out that student behaviour reflects four major SM addiction symptoms namely: preoccupation, adverse consequences, alleviation of negative emotions, and loss of interest in social activities. Academics should channel the strengths of the students in the right direction and encourage healthy usage of SM. With proper care and guidance they can increase the academic performances of students by integrating SM in day to day educational presentation.

Welch (2012:252) also found that excessive and inappropriate internal communication could be "... a source of irritation to employees", because top-down communication using electronic media could portray an image of organisational power.

Users sometimes lose sight of the fact that they are in control of their environment and that no one else who are following them, or who they are following, is in any way in control in the real world by any stretch of the imagination. People should learn to "shut the door" when they feel uncomfortable using SM. Similarly, users should not become obsessed with the number of followers or friends they have or don't have. Users should however not miss out on great opportunities for learning which exist via SM and only refrain from doing so if it becomes negative. Furthermore, it must also be noted that academics do not seem keen to position themselves as their students' friends or equals or to engage in personal disclosures (Veletsianos \& Kimmons 2013).

It is becoming customary for the users of SM to see it as part of their daily life and daily activities, but with an understanding of the accompanying downside to it. In order to determine lecturers' perceptions of the use of SM networking systems in tertiary institutions (higher education), the five constructs of the Technology Acceptance Module was studied. These are discussed in the next section.

\subsection{Technology Acceptance Model (TAM)}

The technology acceptance model (TAM) is an information system theory ${ }^{1}$ that demonstrates how users accept and use specific technology (Davis 1993:475). The model indicates that when users are confronted with a new software package, various factors influence their decision about how and when they will use this specific technology (Mazhar 2006). Davis, Bagozzi \& Warshaw (1989:985) indicated that user motivation can be explained by three constructs; 'Perceived ease of use', 'Perceived usefulness', and 'Attitude toward using the system'.

The first construct is 'Perceived usefulness' which is described according to Davis (1993:477) as, "... the degree to which an individual believes that using a particular system would enhance his or her job performance". The second construct which is 'Perceived ease of use', is defined as, "... the degree to which an individual believes that using a particular system would be free from effort" (Davis 1993:477- 478). The third construct is 'Attitude towards using' and is defined as, "... the degree of evaluative affect that an individual associates with using the target system in his or her job" (Davis 1993:478). The fourth construct that was being tested, was that of 'System accessibility' which refers

${ }^{1}$ System that consists of all the network communication channels used within an organisation. 
to organisational context variables, and the last construct was that of 'Intention to Use', which refers to the degree to which a person has created a conscious plan to perform or not perform a future behaviour (Venkatesh 2013).

\section{Methodology}

This research study was executed after an ethics application was submitted and subsequently approved by the Ethics and Research Committee of the educational institution where the research was executed. However, due to the confidentially of the project, the name of the educational institution cannot be revealed. The results and implications are, however, applicable to the current educational environment in New Zealand, but could perhaps be applied to the tertiary educational systems in other countries as well.

The Questionnaire was based on an existing survey used by another educational institution where it was validated. Minor changes were made to suit the New Zealand environment for example, removing regions and styles of teaching which are not applicable to the institution being used to gain responses from academics in New Zealand.

After the online questionnaire was made available via survey monkey, various reminders were sent to eligible staff and after two months it was closed. Useable responses totalled 58.

The majority of lecturers $(45.71 \%)$ were 56 years or older. The gender split for the respondent group is male dominated, with $59 \%$ of lecturers being male. Most of the respondents are Lecturers or Senior Lecturers $(54.29 \%$ and $28.57 \%$ respectively). Most lecturers were employed between 0 and 5 years. It is evident from the missing responses that more than a third (39.66\%) of the questions was left unanswered by the respondents. The demographic profile of the respondent group is presented in Table 1.

\begin{tabular}{|c|c|c|c|c|c|}
\hline Age group & $\%$ of Total & $\mathbf{N}$ & Position & $\%$ of Total & $\mathbf{N}$ \\
\hline$<25$ & $2.86 \%$ & 1 & Research Assistant & $2.86 \%$ & 1 \\
\hline $26-30$ & $0 \%$ & & Junior Lecturer & $0 \%$ & \\
\hline $31-35$ & $14.29 \%$ & 5 & Lecturer & $54.29 \%$ & 19 \\
\hline $36-40$ & $8.57 \%$ & 3 & Senior Lecturer & $28.57 \%$ & 10 \\
\hline $41-45$ & $2.86 \%$ & 1 & Associate Professor & $0 \%$ & \\
\hline $46-50$ & $2.86 \%$ & 1 & Professor & $2.86 \%$ & 1 \\
\hline $51-55$ & $22.86 \%$ & 8 & Other & $11.43 \%$ & 4 \\
\hline $56+$ & $45.71 \%$ & 16 & Missing responses & $39.66 \%$ & 23 \\
\hline Missing responses & $39.66 \%$ & 23 & & & \\
\hline Gender & $\%$ of Total & $\mathbf{N}$ & Years Employed & $\%$ of Total & $\mathbf{N}$ \\
\hline Male & $58.82 \%$ & 20 & $0-5$ & $42.86 \%$ & 15 \\
\hline Female & $41.18 \%$ & 14 & $6-10$ & $17.14 \%$ & 6 \\
\hline \multirow[t]{4}{*}{ Missing responses } & $41.38 \%$ & 24 & $11-15$ & $28.57 \%$ & 10 \\
\hline & & & $16-20$ & $8.57 \%$ & 3 \\
\hline & & & $20+$ & $2.86 \%$ & 1 \\
\hline & & & Missing responses & $39.66 \%$ & 23 \\
\hline
\end{tabular}

Table 1. Demographic profile

\section{Results}

In the results section the use of SM and communication with students via SM are discussed. The discussion only reflects usable responses received from the respondents.

\subsection{Social media account and communication}

The respondents were asked to indicate if they have a SM account and whether they think it is important to communicate with students on SM. The majority of respondents $(86 \%)$ indicated that they do have a SM account whereas $14 \%$ of the respondents did not have a SM account. Almost two thirds $(61 \%)$ of respondents indicated that they do not think it is important to communicate with 
their students via SM whereas more than a third (39\%) do think it is important to communicate with students using social media, figure 2 below. The majority (52\%) of the respondents who has a SM account is of the opinion that it is not important to communicate with students via this medium. $60 \%$ of the respondents without a social media account shared in this opinion as shown in Table 2.

Figure 2. Social media account and communication with students

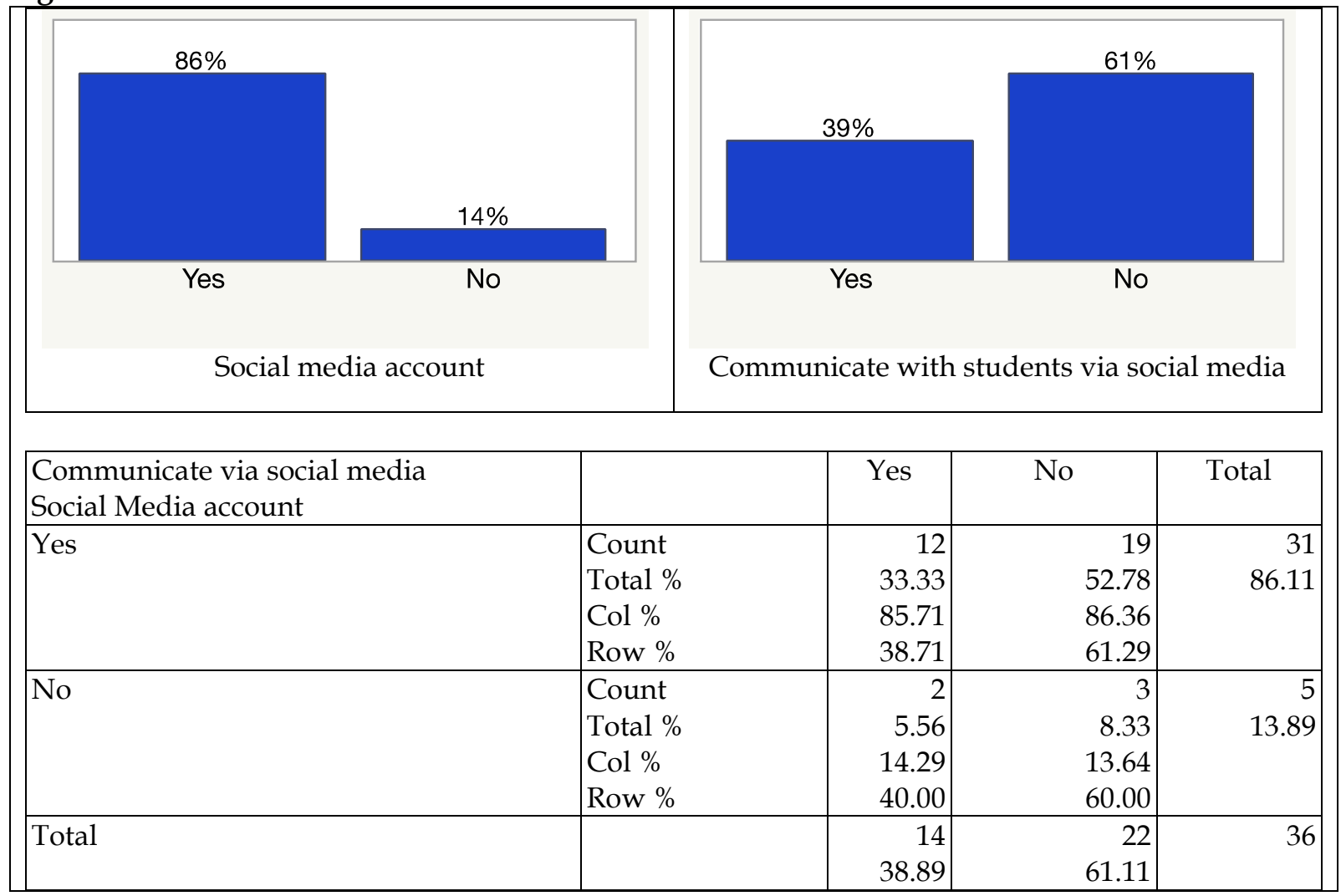

Table 2. Social media usage

In table 3 below, the respondents who indicated that they have a SM account were asked to indicate the type and usage of the account.

\begin{tabular}{|c|c|c|c|c|c|c|c|c|}
\hline & Use this $p$ & tfform & Nun & yer of hov & rs use per & veek, yes 1 & sponses & only \\
\hline $\begin{array}{l}\text { Social Media } \\
\text { platform }\end{array}$ & $\mathrm{No}$ & Yes & $0-5$ & $6-10$ & $11-15$ & $16-20$ & $>21$ & $\begin{array}{l}\text { Total yes } \\
\text { responses }\end{array}$ \\
\hline Facebook & $\begin{array}{r}35 \\
60.3 \%\end{array}$ & \begin{tabular}{r|}
23 \\
$39.7 \%$
\end{tabular} & $\begin{array}{r}12 \\
52.2 \%\end{array}$ & \begin{tabular}{r|}
4 \\
$17.4 \%$
\end{tabular} & \begin{tabular}{r|}
2 \\
$8.7 \%$
\end{tabular} & \begin{tabular}{r|}
4 \\
$17.4 \%$
\end{tabular} & $\begin{array}{r}1 \\
4.3 \%\end{array}$ & 23 \\
\hline \begin{tabular}{|l|} 
LinkedIn \\
\end{tabular} & $\begin{array}{r}33 \\
56.9 \% \\
\end{array}$ & $\begin{array}{r}25 \\
43.1 \%\end{array}$ & $\begin{array}{r}23 \\
92.0 \%\end{array}$ & \begin{tabular}{r|}
1 \\
$4.0 \%$
\end{tabular} & $\begin{array}{r}1 \\
4.0 \%\end{array}$ & \begin{tabular}{r|}
0 \\
$0.0 \%$
\end{tabular} & \begin{tabular}{r|}
0 \\
$0.0 \%$
\end{tabular} & 25 \\
\hline Twitter & $\begin{array}{r}49 \\
84.5 \% \\
\end{array}$ & $\begin{array}{r}9 \\
15.5 \% \\
\end{array}$ & $\begin{array}{r}8 \\
88.9 \% \\
\end{array}$ & $\begin{array}{r}1 \\
11.1 \% \\
\end{array}$ & $\begin{array}{r}0 \\
0.0 \%\end{array}$ & $\begin{array}{r}0 \\
0.0 \%\end{array}$ & $\begin{array}{r}0 \\
0.0 \% \\
\end{array}$ & 9 \\
\hline Mxit & $\begin{array}{r}58 \\
100.0 \% \\
\end{array}$ & $\begin{array}{r}0 \\
0.0 \% \\
\end{array}$ & 0 & 0 & 0 & 0 & 0 & 0 \\
\hline MySpace & $\begin{array}{r}56 \\
96.6 \% \\
\end{array}$ & \begin{tabular}{r|}
2 \\
$3.4 \%$ \\
\end{tabular} & $\begin{array}{r}1 \\
50.0 \% \\
\end{array}$ & $\begin{array}{r}1 \\
50.0 \% \\
\end{array}$ & $\begin{array}{r}0 \\
0.0 \% \\
\end{array}$ & $\begin{array}{r}0 \\
0.0 \% \\
\end{array}$ & $\begin{array}{r}0 \\
0.0 \% \\
\end{array}$ & 2 \\
\hline Blogs & $\begin{array}{r}49 \\
84.5 \%\end{array}$ & \begin{tabular}{r|}
9 \\
$15.5 \%$
\end{tabular} & $\begin{array}{r}9 \\
100.0 \%\end{array}$ & \begin{tabular}{r|}
0 \\
$0.0 \%$
\end{tabular} & \begin{tabular}{r|}
0 \\
$0.0 \%$
\end{tabular} & \begin{tabular}{r|}
0 \\
$0.0 \%$
\end{tabular} & \begin{tabular}{r|}
0 \\
$0.0 \%$
\end{tabular} & 9 \\
\hline YouTube & $\begin{array}{r}41 \\
70.7 \% \\
\end{array}$ & $\begin{array}{r}17 \\
29.3 \% \\
\end{array}$ & $\begin{array}{r}11 \\
64.7 \%\end{array}$ & $\begin{array}{r}3 \\
17.6 \%\end{array}$ & $\begin{array}{r}0 \\
0.0 \%\end{array}$ & $\begin{array}{r}3 \\
17.6 \%\end{array}$ & $\begin{array}{r}0 \\
0.0 \%\end{array}$ & 17 \\
\hline Pinterest & 52 & 6 & 5 & 0 & 0 & 1 & 0 & 6 \\
\hline
\end{tabular}




\begin{tabular}{|l|r|r|r|r|r|r|r|r|}
\hline & $89.7 \%$ & $10.3 \%$ & $83.3 \%$ & $0.0 \%$ & $0.0 \%$ & $16.7 \%$ & $0.0 \%$ & \\
\hline Institution & 31 & 27 & 13 & 6 & 6 & 1 & 1 & 27 \\
system & $53.4 \%$ & $46.6 \%$ & $48.1 \%$ & $22.2 \%$ & $22.2 \%$ & $3.7 \%$ & $3.7 \%$ & \\
\hline Instagram & 52 & 6 & 3 & 0 & 1 & 2 & 0 & 6 \\
& $89.7 \%$ & $10.3 \%$ & $50.0 \%$ & $0.0 \%$ & $16.7 \%$ & $33.3 \%$ & $0.0 \%$ & \\
\hline Tumblr & 41 & 17 & 13 & 3 & 0 & 1 & 0 & 17 \\
& $70.7 \%$ & $29.3 \%$ & $76.5 \%$ & $17.6 \%$ & $0.0 \%$ & $5.9 \%$ & $0.0 \%$ & \\
\hline Google+ & 56 & 2 & 2 & 0 & 0 & 0 & 0 & 2 \\
& $96.6 \%$ & $3.4 \%$ & $100.0 \%$ & $0.0 \%$ & $0.0 \%$ & $0.0 \%$ & $0.0 \%$ & \\
\hline
\end{tabular}

Table 3. Usage of social media accounts

It is clear from the table that the platforms most used by the respondents, are the institution system (46.6\%); LinkedIn (43.1\%) and Facebook (39.7\%). The majority of the respondents do not use Mixit (100\%); MySpace (96.6\%); Google+ (96.6\%); Pinterest (89.7\%) and Instagram (89.7\%). More than half the respondents spend five or less hours per week on a social media platform. Only one respondent, not necessary the same respondent, indicated that he/she spend twenty hours or more per week on Facebook and the institution system.

\subsection{Use of social media to enhance learning}

The respondents were asked to indicate the use of SM as academics to enhance student learning on a seven-point Likert scale. The items used are borrowed from the Technology acceptance model, see table 4 .

\begin{tabular}{|c|c|c|c|c|c|c|c|c|c|}
\hline \multirow[t]{2}{*}{ Item } & \multicolumn{7}{|c|}{$\%$ of Total } & \multirow[t]{2}{*}{$\mathbf{N}$} & \multirow[t]{2}{*}{ Mean } \\
\hline & 1 & 2 & 3 & 4 & 5 & 6 & 7 & & \\
\hline $\begin{array}{l}\text { I found social network systems } \\
\text { easy to use. }\end{array}$ & $5.13 \%$ & $7.69 \%$ & $0.00 \%$ & $20.51 \%$ & $17.95 \%$ & $33.33 \%$ & $15.38 \%$ & 39 & 5.00 \\
\hline $\begin{array}{l}\text { Learning to use social network } \\
\text { systems would be easy for me. }\end{array}$ & $5.13 \%$ & $5.13 \%$ & $5.13 \%$ & $17.95 \%$ & $12.82 \%$ & $35.90 \%$ & $17.95 \%$ & 39 & 5.08 \\
\hline $\begin{array}{l}\text { My interaction with social } \\
\text { network systems is clear and } \\
\text { understandable. }\end{array}$ & $5.13 \%$ & $5.13 \%$ & $10.26 \%$ & $12.82 \%$ & $17.95 \%$ & $28.21 \%$ & $20.51 \%$ & 39 & 5.00 \\
\hline $\begin{array}{l}\text { It would be easy for me to find } \\
\text { information on social network } \\
\text { systems. }\end{array}$ & $5.13 \%$ & $7.69 \%$ & $12.82 \%$ & $10.26 \%$ & $15.38 \%$ & $33.33 \%$ & $15.38 \%$ & 39 & 4.85 \\
\hline $\begin{array}{l}\text { It is easy to become skilful at } \\
\text { using social network systems. }\end{array}$ & $2.56 \%$ & $7.69 \%$ & $7.69 \%$ & $17.95 \%$ & $17.95 \%$ & $23.08 \%$ & $23.08 \%$ & 39 & 5.03 \\
\hline $\begin{array}{l}\text { Using social network systems } \\
\text { would enhance my effectiveness } \\
\text { in teaching. }\end{array}$ & $5.13 \%$ & $10.26 \%$ & $15.38 \%$ & $25.64 \%$ & $20.51 \%$ & $12.82 \%$ & $10.26 \%$ & 39 & 4.26 \\
\hline $\begin{array}{l}\text { Using social network systems } \\
\text { would improve my course } \\
\text { performance. }\end{array}$ & $5.13 \%$ & $15.38 \%$ & $10.26 \%$ & $28.21 \%$ & $17.95 \%$ & $17.95 \%$ & $5.13 \%$ & 39 & 4.13 \\
\hline $\begin{array}{l}\text { Using social network systems } \\
\text { would increase my productivity } \\
\text { in my teaching work. }\end{array}$ & $7.69 \%$ & $15.38 \%$ & $12.82 \%$ & $23.08 \%$ & $20.51 \%$ & $17.95 \%$ & $2.56 \%$ & 39 & 3.97 \\
\hline $\begin{array}{l}\text { I found social network systems } \\
\text { useful. }\end{array}$ & $10.26 \%$ & $10.26 \%$ & $2.56 \%$ & $30.77 \%$ & $20.51 \%$ & $20.51 \%$ & $5.13 \%$ & 39 & 4.23 \\
\hline $\begin{array}{l}\text { Social network systems could } \\
\text { make it easier to study course } \\
\text { content. }\end{array}$ & $5.13 \%$ & $10.26 \%$ & $7.69 \%$ & $28.21 \%$ & $25.64 \%$ & $15.38 \%$ & $7.69 \%$ & 39 & 4.36 \\
\hline $\begin{array}{l}\text { I dislike the idea of using social } \\
\text { network systems. }\end{array}$ & $17.95 \%$ & $20.51 \%$ & $12.82 \%$ & $20.51 \%$ & $7.69 \%$ & $10.26 \%$ & $10.26 \%$ & 39 & 3.51 \\
\hline
\end{tabular}

www.jbrmr.com A Journal of the Academy of Business and Retail Management (ABRM) 


\begin{tabular}{|c|c|c|c|c|c|c|c|c|c|}
\hline Item & \multicolumn{7}{|c|}{$\%$ of Total } & $\mathbf{N}$ & Mean \\
\hline & 1 & 2 & 3 & 4 & 5 & 6 & 7 & & \\
\hline $\begin{array}{l}\text { I have a generally favourable } \\
\text { attitude towards using social } \\
\text { network systems. }\end{array}$ & $10.26 \%$ & $7.69 \%$ & $2.56 \%$ & $20.51 \%$ & $17.95 \%$ & $30.77 \%$ & $10.26 \%$ & 39 & 4.62 \\
\hline $\begin{array}{l}\text { I believe it is (would be) a good } \\
\text { idea to use social network } \\
\text { systems for my teaching work. }\end{array}$ & $5.26 \%$ & $7.89 \%$ & $18.42 \%$ & $31.58 \%$ & $15.79 \%$ & $13.16 \%$ & $7.89 \%$ & 38 & 4.16 \\
\hline $\begin{array}{l}\text { Using social network systems is a } \\
\text { foolish idea. }\end{array}$ & $26.32 \%$ & $23.68 \%$ & $13.16 \%$ & $18.42 \%$ & $7.89 \%$ & $2.63 \%$ & $7.89 \%$ & 38 & 2.97 \\
\hline $\begin{array}{l}\text { I am positive towards social } \\
\text { network systems. }\end{array}$ & $2.63 \%$ & $7.89 \%$ & $7.89 \%$ & $26.32 \%$ & $15.79 \%$ & $23.68 \%$ & $15.79 \%$ & 38 & 4.79 \\
\hline $\begin{array}{l}\text { I intend to use social network } \\
\text { systems during the semester for } \\
\text { teaching purposes. }\end{array}$ & $7.89 \%$ & $18.42 \%$ & $7.89 \%$ & $23.68 \%$ & $18.42 \%$ & $5.26 \%$ & $18.42 \%$ & 38 & 4.16 \\
\hline $\begin{array}{l}\text { I will return to social network } \\
\text { systems often. }\end{array}$ & $7.89 \%$ & $13.16 \%$ & $15.79 \%$ & $23.68 \%$ & $13.16 \%$ & $15.79 \%$ & $10.53 \%$ & 38 & 4.11 \\
\hline $\begin{array}{l}\text { I intend to visit social network } \\
\text { systems frequently for my } \\
\text { teaching work. }\end{array}$ & $10.53 \%$ & $15.79 \%$ & $15.79 \%$ & $23.68 \%$ & $10.53 \%$ & $13.16 \%$ & $10.53 \%$ & 38 & 3.89 \\
\hline $\begin{array}{l}\text { I intend to be a heavy user of } \\
\text { social network systems. }\end{array}$ & $13.16 \%$ & $21.05 \%$ & $13.16 \%$ & $21.05 \%$ & $21.05 \%$ & $2.63 \%$ & $7.89 \%$ & 38 & 3.55 \\
\hline $\begin{array}{l}\text { I intend to use social network } \\
\text { systems for communicating with } \\
\text { others. }\end{array}$ & $5.26 \%$ & $15.79 \%$ & $13.16 \%$ & $15.79 \%$ & $21.05 \%$ & $15.79 \%$ & $13.16 \%$ & 38 & 4.32 \\
\hline $\begin{array}{l}\text { What social network systems } \\
\text { stand for is important for me as a } \\
\text { university lecturer. }\end{array}$ & $7.89 \%$ & $18.42 \%$ & $5.26 \%$ & $26.32 \%$ & $21.05 \%$ & $13.16 \%$ & $7.89 \%$ & 38 & 4.05 \\
\hline $\begin{array}{l}\text { I like using social network } \\
\text { systems based on the similarity of } \\
\text { my values and society values } \\
\text { underlying its use. }\end{array}$ & $7.89 \%$ & $18.42 \%$ & $13.16 \%$ & $28.95 \%$ & $15.79 \%$ & $13.16 \%$ & $2.63 \%$ & 38 & 3.76 \\
\hline $\begin{array}{l}\text { In order for me to prepare } \\
\text { students for their future careers, it } \\
\text { is necessary to take social } \\
\text { network systems courses. }\end{array}$ & $13.16 \%$ & $18.42 \%$ & $7.89 \%$ & $26.32 \%$ & $10.53 \%$ & $23.68 \%$ & $0.00 \%$ & 38 & 3.74 \\
\hline $\begin{array}{l}\text { I have no difficulty accessing and } \\
\text { using an e-learning system in the } \\
\text { university. }\end{array}$ & $2.63 \%$ & $2.63 \%$ & $5.26 \%$ & $13.16 \%$ & $10.53 \%$ & $18.42 \%$ & $47.37 \%$ & 38 & 5.71 \\
\hline
\end{tabular}

Table 4 . Items on the use of social media by academics to enhance student learning

It is evident from the table that the average score on a 7-point Likert scale are all above 3.5except for the item - "Using social network systems is a foolish idea" $(M=2.97)$. It can thus be inferred that the respondents are positive about using SM in their teaching. The three items with the highest average scores are "I have no difficulty accessing and using an e-learning system in the university" $(M=$ 5.71), "Learning to use social network systems would be easy for me" $(M=5.08)$ and, "It is easy to become skilful at using social network systems" $(M=5.03)$.

\subsection{Constructs}

The items used are borrowed from the technology acceptance model and can be grouped in five constructs, (perceived ease of use; perceived usefulness; attitude towards using; intention to use 
and subjective norm), see table 5. Due to the number of responses, the fact that TAM is well researched and the constructs are confirmed, no confirmatory factor analysis was performed.

\begin{tabular}{|l|c|c|c|c|}
\hline Constructs & $\mathbf{N}$ & Mean & Standard Deviation & $\begin{array}{c}\text { Cronbach's alpha } \\
\text { value (a) }\end{array}$ \\
\hline Ease of use 1-5 & 39 & 4.99 & 1.61 & .97 \\
\hline Usefulness 6-10 & 39 & 4.19 & 1.42 & .92 \\
\hline Attitude 11-15 & 39 & 4.61 & 1.26 & .76 \\
\hline Intention 16-20 & 38 & 4.01 & 1.61 & .93 \\
\hline Subjective norm 21-23 & 38 & 3.85 & 1.51 & .87 \\
\hline
\end{tabular}

Table 5. Technology acceptance model constructs

It is evident from the table that the average score of the constructs on a 7-point Likert scale, are all above 3.5. The construct ease of use has the highest mean score $(M=4.99)$ and the subjective norm has the lowest mean score $(M=3.85)$. The constructs were all found reliable with Cronbach's alpha values of well above .60. Perceived ease of use consisting of 5 items $(1-5)$ has the highest Cronbach's alpha value $(\alpha=.97)$ whereas attitude towards using consisting of 5 items $(11-15)$ has the lowest Cronbach's alpha value $(\alpha=.76)$.

\subsection{Profiling the usage of social media by respondents}

The biographical variables age, gender, years of employment and position were tested against the usage of social media as well as the importance to communicate with students via SM. No significant differences were found in usage.

\section{Limitations of the study}

The study was only conducted at one tertiary educational institution in New Zealand in 2015 and the results should therefore be viewed with caution as it is only a limited snapshot of the need for, and use of SM in New Zealand. A comparison of the needs and use of SM from the learners' point of view was not addressed in this research study and should be undertaken in the near future. Also not addressed in the study, is a comparison with the state of use of SM in other countries. Further studies in this regard could shed light on the global state of affairs. This study could, however, give an indication on where New Zealand is with the use of SM at tertiary educational institutions. As it was beyond the scope of this research, no attempt was made to investigate the use of SM at secondary school level either. This could however certainly be considered in future for comparative purposes and also to reveal the readiness of pupils to embrace SM at tertiary level should they continue their studies.

It is suggested that a study be conducted to cover various tertiary educational institutions throughout New Zealand to gain a more representative view of what the actual use and need for SM is in New Zealand. A limiting factor is the number of responses received back and the results can therefore not be generalised.

\section{Discussion and conclusion}

Due to daily changes in technology, people are more enabled to become informed and aware of the different types of technological systems as opposed to a few years ago. The use of the internet has further enabled many people, students, lecturers and institutions around the world to communicate more effectively with each other on specific topics and issues at any point in time (Mangold \& Faulds, 2009:357). It therefore becomes evident that the use of SM networking systems in tertiary institutions does not only simplify communication between them and the students, but it can also add a lot of value by encouraging discussions between and among students, as well as addressing administrative issues (Moran, Seaman \&Tinti-Kane2011:4).

The findings of the study revealed that $86 \%$ of the respondents have a SM account and from those respondents who do have an account, $39 \%$ think it is important to communicate with students 
on SM. The most used platforms are the institution's systems, LinkedIn and Facebook and the majority of the respondents who are using a platform, spend less than five hours per week on the platform. It is clear that the respondents in general found SM easy to use and useful. They have a positive attitude towards SM and intend to use it in future.

Results of similar studies in South Africa suggested that there were biographical differences for age-group and gender when it comes to the use of SM as a lecturing tool. However the findings of this study suggest that there are no significant differences between the biographical differences and the SM as lecturing tool. However one should not lose sight of the number of response in the last study.

It is clear that the use of SM has become an essential aspect of the toolkit of academics to enhance their teaching and to improve the learning environment for students. It is accompanied by the fact that the learning environment can become more interactive and exciting for the learners and also infuse enthusiasm for both teachers and learners by employing the tools that are available. The positive is that SM broadens a person's mind and their perception of things they can do or help them to do. As pointed out in the research results there are however challenges in New Zealand regarding its use in the educational environment.

\section{References}

Davis, F.D. (1993).'User acceptance of information technology: system characteristics, user perceptions and behavioural impacts', International Journal of Man-Machine Studies, 38(1), 475487.

Davis, F.D., Bagozzi, R.P. \& Warshaw, P.R. (1989). ‘User Acceptance of Computer Technology: Comparison of Two Theoretical Models', Management Science, 35(8):982-1003.

Dixon, G. (2015). 'Social Media 101', Canvas Magazine. Supplement to the NZ Weekend Herald. 17 January 2015, pp.9-12.

Education Council NZ. (2015a). What is Social Media? Retrieved from:

http:/ / academicsandsocialmedia.co.nz/what-social-media

Education Council NZ. (2015b). Communication and collaboration in learning. Retrieved from:

http:/ / teachersacademicsandsocialmedia.co.nz/your-stories/positive-case-

studies/communication-and-collaboration-learning

Fuatai, T. (2012). One in five kiwis 'like' Facebook use at work. Retrieved from:

http:/ / www.nzherald.co.nz/news/print.cfm?objectid=10813136

Huang, H. (2014). Social Media Generation in Urban China: A Study of Social Media Use and Addiction among Adolescents. Heidelberg, Germany: Springer.

Lupton, D. (2014). 'Feeling Better Connected': Academics' Use of Social Media. Retrieved from:

http:/ / www.canberra.edu.au/research/faculty-researchcentres/nmrc/publications/documents/Feeling-Better-Connected-report-final.pdf

Mangold, W. G. \& Faulds, D. J. (2009). 'Social media; the new hybrid element of the promotion mix', Business Horizons, 52: 357-365.

Mazhar, N. (2006). Technology Acceptance Model. [Online] Available from:

http:/ / ezinearticles.com/?Technology-Acceptance-Model\&id=202354 [Accessed 18-February 2013]

Moran, M., Seaman, J. \& Tinti-Kane, H. (2011). Teaching, Learning and Sharing: How today's higher education faculty use social media. [Online] Available from:

http:/ / www.pearsonlearningsolutions.com/educators/pearson-social-media-survey-2011-bw.pdf [Accessed: 21-01-2013]

Neal, D.R. (2012). Social Media for Academics: A Practical Guide. Oxford: Chandos Publishing.

Nel, P.S. (2013). 'New Zealand HR employee communication: Comparing 2000 and 2010 empirical results with forecasts for 2020', Journal of Business and Policy Research, 8(1): 132-146. March.

Rahman, N., Arora, J. \& Kularatne, I. (2014). 'Employers' perceptions of using social media for recruitment', Asia Pacific Journal of Business and Management2014, 5(1): 1-12 
Research New Zealand. (2015). A Report on a Survey of New Zealanders' Use of Smartphone's and other Mobile Communication Devices 2015. Retrieved from:

http://www.researchnz.com/pdf/Special\%20Reports/

Research\%20New\%20Zealand\%20Special\%20Report\%20-\%20Use\%20of\%20Smartphones.pdf

Retta, G. (2012). 'The use of social media for academic practice: a review of literature', Kentucky Journal of Higher Education Policy and Practice, 1(I). 2, Article 7

Seaman, J. \& Tinti-Kane, H. (2013). Social Media for Teaching and Learning. Retrieved from:

http://www.pearsonlearningsolutions.com/assets/downloads/reports/social-media-for-teachingand-learning-2013-report.pdf

SHRM. (2012). January. SHRM research spotlight: Social media in business strategy and operations. Retrieved from:

http://www.shrm.org/Research/SurveyFindings/Documents/Part_4_Social_Media_Flier.pdf

Taylor, C. (2015). Does Facebook 'unfriending' constitute bullying? Retrieved from

http://www.hrmonline.co.nz/news/does-facebook-unfriending-constitute-bullying-206104.aspx

Veletsianos, G. \& Kimmons, R. (2013). 'Scholars and faculty members' lived experiences in online social networks', The Internet and Higher Education, 16: 43-50.

Venkatesh, V. (2013). Unified Theory of Acceptance and Use of Technology (UTAUT). [online] Available from: http://www.vvenkatesh.com/it/organizations/theoretical_models.asp [Accessed: 17 May 2013].

Welch, M. (2012). 'Appropriateness and acceptability: Employee perspectives of internal communication', Public Relations Review, 38(2): 246-254. doi:10.1016/j.pubrev.2011.12.017

Wiid, J.A. Nell, E.C. \& Cant, M.C. (2015). 'Perceptions of lecturing staff on social media networking systems and their use of it', International Business E Economics Research Journal, 14(3): 395-406.

White, C. Vanc, A. \& Stafford, G. (2010). 'Internal communication, information satisfaction, and sense of community: The effect of personal influence', Journal of Public Relations Research, 22(1): 65-84. Doi:10.1080/10627260903170985.

Young, C. (2014). Could the use of eLearning and digital literacy tools improve CAA's business goals of increased student retention and student success? Unpublished MBA thesis. Unitec, New Zealand. 